\title{
Single-step Synthesis and Characterization of Zr-MOF onto Wool Fabric: Preparation of Antibacterial Wound Dressing with High Absorption Capacity
}

\author{
Reihane Rezaee $^{1}$, Majid Montazer ${ }^{1 *}$, Ali Mianehro ${ }^{1}$, and Mahnaz Mahmoudirad ${ }^{2}$ \\ ${ }^{1}$ Department of Fiber Sciences and Textile Engineering, Amirkabir University of Technology, Tehran 1591634311, Iran \\ ${ }^{2}$ Skin Research Center, Shahid Beheshti Medical Sciences, Tehran 1983969411, Iran
}

(Received March 17, 2021; Revised April 29, 2021; Accepted May 31, 2021)

\begin{abstract}
Improvement of curative herbal extracts effectiveness through novel drug delivery systems is a field of study for the researches nowadays. Zirconium-based metal-organic frameworks (Zr-MOFs) are one of the most capable porous nanocarriers that need a biocompatible template to be used in biomedical applications. In this work, Zr-MOF was synthesized into the wool fabric through in-situ one-pot method with different molar ratios. The final fabrics were characterized thoroughly using various techniques and the effect of components on monodispersity and nucleation tendency of Zr-MOF onto the surface of wool were explained. The resultant fabric stablished absolute wash durability, increased air-permeability up to twice and reasonable hydrophilicity. Tensile strength and young modulus decreased 30 and $1244 \%$ and strain increased $66 \%$. Salvia Officinalis (SO) and Calendula Officinalis (CO) extracts were loaded onto the modified fabrics with 1154 and $1842 \%$ increased absorption capacity. The release profiles showed domination of diffusion mechanism. The wool-MOF-SO and CO displayed both $100 \%$ antibacterial activity against Escherichia coli and 60.95 and $64.64 \%$ against Staphylococcus aureus because of diverse antibacterial components. Calendula Officinalis proved biocompatibility with human skin however Salvia Officinalis exhibited high toxicity.
\end{abstract}

Keywords: Zirconium-based metal-organic framework (Zr-MOF), Antibacterial wool fabric, Herbal extracts, Release kinetic, In-situ synthesis

\section{Introduction}

In recent decade, increase of drug effectiveness and decrease of side effects of high concentration drugs scattered on body cells have drawn lots of attention. Hence, local drug delivery, targeted drug delivery, drug release rate control, enhanced cell penetration and internalization have been the subject of numerous researches [1-11]. Diverse nanocarriers were used to achieve the mentioned goal such as metalorganic frameworks (MOFs) as the most tunable nanocarriers with tailored size of pores and functional groups and the uniform structure [12-16]. In particular, zirconium-based MOFs attracted great deal of attention for the high structural and thermal stabilities [17-19].

MOFs are usually synthesized on a template to increase their efficiency and possess favorable properties [20]. Textiles are the most used template for MOFs with desirable mechanical properties [21]. Different types of MOFs can introduce diverse properties including UV protection, photocatalytic and high absorption capacity [22-25].

Medicinal herbs have been used from prehistoric times to the present. About 35000 species, two third of herbs, showed medicinal properties also 7000 herbs indexed in modern pharmacopoeia [26]. However, most of them have low solubility in biological environments led to the drastic influences on their effectiveness. Modern drug delivery methods increase their absorption, bioavailability and structural stability also limit burst release, lowering

*Corresponding author: tex5mm@aut.ac.ir cytotoxicity and enhance prolonged release to the targeted tissues. This consequently can revive utilization of medicinal herbs in modern medicine [27].

Among medicinal herbs, Salvia Officinalis has been widely used for centuries. It has very strong antioxidant, antibacterial and radical scavenging activities and functions as nerve stimulator, anti-Alzheimer, carminative, soothing and anticancer agent [28-30]. Another medicinal herb, Calendula Officinalis, is extensively used clinically for dermatological disorders and periodontitis. Recent researches have revealed its effect on stimulation proliferation and migration of fibroblasts. Furthermore, it has antibacterial, antioxidant, antifungal, anti-inflammatory, nerve stimulation and disinfectant properties [31-35]. The extract of both mentioned herbs is mainly constituted of oxygenated monoterpenes, monoterpene hydrocarbons, sesquiterpene hydrocarbons and oxygenated sesquiterpenes [36]. Very recent researches interestingly demonstrate that both of these extracts make a stable complex with COVID-19 (SARSCoV-II) main protease and papain like protease consequently hinder replication which can arise interest as anti-COVID19 drugs [37,38].

To our knowledge, there is no report on the synthesis of any type of $\mathrm{Zr}$-MOFs onto the surface of wool. In this research Zr-MOF was synthesized in single-step onto the surface of wool, a natural biocompatible substrate, then characterized thoroughly by various methods and hypothetical interaction mechanism was postulated. Based on mentioned healing properties of Salvia Officinalis and Calendula Officinalis, they were loaded on the wound-dressing fabric 
then the release rate, antibacterial activity and cytotoxicity were investigated. Also, relation between chemical composition of herbal extracts and their attributes were described.

\section{Experimental}

\section{Materials}

Wool fabric was purchased from Iran Merinos Co. and zirconium oxide chloride octahydrate, terephthalic acid, dimethylformamide (DMF), sodium hydroxide, acetic acid and phosphate-buffered saline (PBS) tablets were purchased from Merck Co. Germany.

\section{Methods}

\section{Pre-treatment}

Raw wool fabric was subjected to different environments during fabrication that should be cleared by washing. Raw wool fabric was washed with $2 \mathrm{~g} / l$ nonionic detergent at $40{ }^{\circ} \mathrm{C}$ for $20 \mathrm{~min}$.

Synthesis of Zr-MOF and In-situ Synthesis of Zr-MOF onto Wool Fabric

Typical synthesis conditions of Zr-MOF may damage wool structure also $\mathrm{Zr}-\mathrm{MOF}$ should nucleate on the surface of wool to establish durability and stability; accordingly, different moderate synthesis conditions and acids including acetic acid, citric acid and hydrochloric acid were investigated. Molar ratio of zirconium oxychloride to terephthalic acid was set 1:1.5 to improve dispersity of Zr-MOF. Two samples were selected with molar ratio of $\mathrm{Zr}$ salt:ligand:modulator at 1:1.5:2.5 labeled as wool-MOF and 1:1.5:25 defined as wool-MOF0.1 for investigating the acid ratio effect. Figure 1 elucidates the synthesis route as Zr-MOF synthesized on the wool fabric based on in-situ one-pot synthesis method. The same route was also used to synthesize $\mathrm{Zr}-\mathrm{MOF}$ powder. To synthesize wool-MOF, initially $0.4 \mathrm{~g}$ wool fabric was immersed in a sealed container consisting of $0.241 \mathrm{~g}$ terephthalic acid dispersed in $12 \mathrm{~m} l$ DMF and heated at $70{ }^{\circ} \mathrm{C}$ for $3 \mathrm{~h}$. Afterwards, $0.322 \mathrm{~g}$ zirconium oxychloride and $0.15 \mathrm{~m} l$ acetic acid were added $(\mathrm{pH}=4)$ at ambient temperature and stirred for $24 \mathrm{~h}$. Lastly, the sample was washed several times with deionized water. Wool-MOF0.1 was prepared using
$0.0241 \mathrm{~g}$ terephthalic acid and $0.0322 \mathrm{~g}$ zirconyl chloride while amount of other chemicals, conditions and processing remained the same.

\section{Characterization and Measurements Characterization}

To study the success of reactions, Fourier transform infrared spectroscopy (FTIR) was utilized in the range of $400-4000 \mathrm{~cm}^{-1}$ with $\mathrm{KBr}$ pellets by Nexus 6700 , PerkinElmer, Germany. The morphology of prepared samples was observed by means of field emission scanning electron microscopy (FESEM) VEGA2-TESCAN, TESCAN, Czech Republic. FESEM was coupled with elemental mapping and energy dispersive X-ray (EDX) analysis to investigate the elemental analysis of samples and distribution evenness. X-ray diffraction analysis (XRD) was performed by EQUINOX 3000, INEL, France to study the crystalline structure of samples.

\section{Structural Simulation}

Structural simulation of $\mathrm{Zr}-\mathrm{MOF}$ based on quantum mechanics theory was accomplished with Gaussian 09 program and corresponding FTIR absorptions were elicited. Optimization of all atom positions was achieved based on ground state of density functional theory (DFT) with either B3LYP or LanL2MP functionals coupled with $6-311++\mathrm{G}$ $(\mathrm{d}, \mathrm{p})$ basis set.

\section{Ultraviolet-visible (UV-vis) Spectroscopy}

For each test, about $3 \mathrm{~m} l$ of solution was dripped in quartz cuvette with $1 \mathrm{~cm}$ path length and spectrum from 200 to $800 \mathrm{~nm}$ was scanned. Baseline was set based on solvent spectrum and each test was three times repeated.

\section{Mechanical Properties}

Samples were cut uniformly into $5 \mathrm{~cm} \times 15 \mathrm{~cm}$ and the mechanical properties of fabrics were determined using Instron 5566 according to British standard for woven fabrics (BS 2576:1967). The initial steep of resultant stress-strain curve was used to determine the Young's modulus of fabrics. Each test was three times repeated and the average was calculated.

\section{Fabric Air-permeability}

The air-permeability properties of samples were determined on DL M021S air-permeability tester supporting from

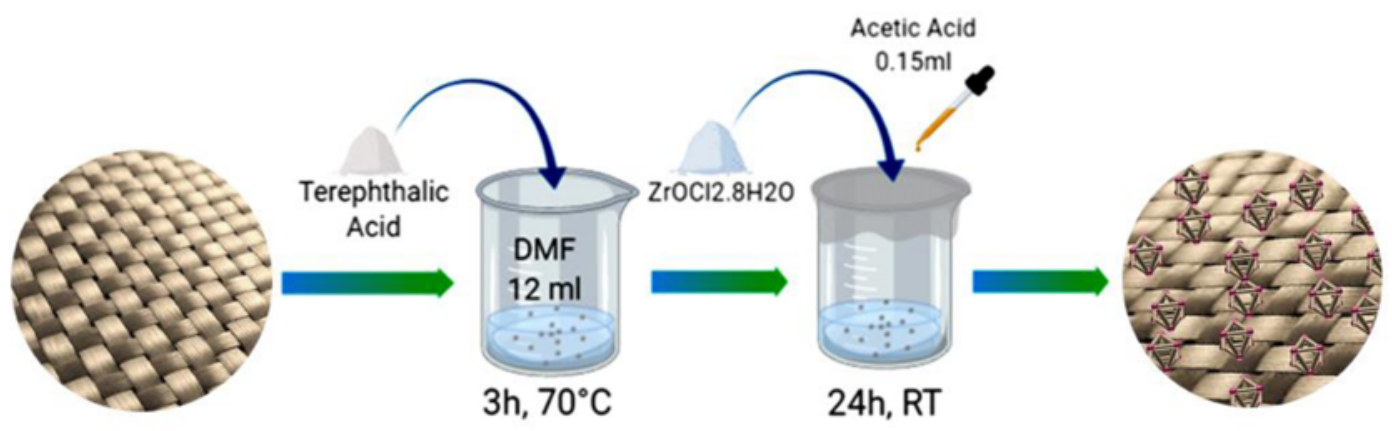

Figure 1. Synthesis route of Zr-MOF onto the surface of wool fabric. 
78.040 to $0.020 \mathrm{~m} / \mathrm{s}^{-1} \mathrm{~cm}^{-2}$ values at $100 \mathrm{~Pa}$ according to ASTM D737 standard. The samples were cut square $5 \mathrm{~cm} \times$ $5 \mathrm{~cm}$ and air-permeability was measured under $100 \mathrm{~Pa}$.

\section{Water Absorbency Rate}

Samples were placed flat and creases were smoothed then water drops were dripped on fabric from $1 \mathrm{~cm}$ height and the time of complete absorption was measured according to AATCC 79 standard. Each sample was five times tested and average was calculated.

\section{Herbal Extraction}

$40 \mathrm{~g}$ of dried herb was added to $300 \mathrm{~m} l$ water and heated at $70{ }^{\circ} \mathrm{C}$ to evaporate the water then herb was crushed and $200 \mathrm{~m} l$ preheated water was added to the crushed herb and heated at $70{ }^{\circ} \mathrm{C}$ to form a concentrated liquid. After filtering, it was boiled for $10 \mathrm{~min}$ to produce highly concentrated extract.

\section{Loading and Release of Herbal Extracts on Wool}

Samples were immersed in $20 \mathrm{~m} l / l$ extract solution for $24 \mathrm{~h}$ and then washed thoroughly with distilled water. The samples were subsequently immersed in phosphate-buffered saline (PBS) solution and release rates were calculated based on UV-vis absorption intensity and corresponding calibration curve. The entrapment efficiency was calculated based on ratio of actual extract loading to theoretical extract loading.

\section{Antimicrobial Activity}

Antibacterial activity of samples containing Zr-MOF and herbal extracts were conducted by colony counting method according to AATCC test method 100 against Escherichia coli as Gram negative and Staphylococcus aureus as Gram positive bacteria. For this purpose, samples were cut in circles with $4.8 \mathrm{~cm}$ diameter and sterilized under UV light for $2 \mathrm{~h}$. The grown bacteria in $10 \mathrm{~m} l$ nutrient broth were shifted to sterile nutrient agar and incubated for $24 \mathrm{~h} .1 \mathrm{ml}$ bacterial suspension $\left(1-2 \times 10^{5} \mathrm{CFU} / \mathrm{m} l\right)$ were dripped in each sample then suspension incubated at $37^{\circ} \mathrm{C}$ for $24 \mathrm{~h}$. Finally, the colonies on the plate were counted and the antibacterial activity calculated based on ratio of the reduced colony number after incubation to colony number before incubation.

\section{Cell Viability}

Briefly, to investigate samples cytotoxicity, $100 \mathrm{~m} l$ solution containing $90 \mathrm{~m} l$ Dulbecco's modified Eagle medium (DMEM) and glutamine and $10 \mathrm{~m} l$ fetal calf serum was prepared. The fibroblasts were separated through trypsinization and counted. Then cells were placed in 96 well plate and incubated at $37{ }^{\circ} \mathrm{C}$ for $48 \mathrm{~h}$ with $5 \% \mathrm{CO}_{2}$. After that, MTT solution $0.5 \mathrm{mg} / \mathrm{m} l$ in PBS was added to each well then incubated at $37{ }^{\circ} \mathrm{C}$ for $64 \mathrm{~h}$ with $5 \% \mathrm{CO}_{2}$. Afterwards, the medium was removed and $0.2 \mathrm{ml} \mathrm{DMSO}$ was added to each well and incubated for $10 \mathrm{~min}$ at $37^{\circ} \mathrm{C}$. The absorption intensity at $570 \mathrm{~nm}$ wavelength was recorded and cell viability was calculated based on ratio of sample absorption to control absorption. Each sample was 5 times tested and average was considered.

\section{Results and Discussion}

\section{Hypothetical Interaction Mechanism of Zr-MOF and Wool Fabric}

Wool has diverse functional groups including carboxyl, hydroxyl, amine and amide which can interact with zirconium oxide clusters and terephthalic acid [39]. Zirconium ions can make coordination and electrostatic interactions. Terephthalic acid molecules can make acid-base interaction with amine and amide groups, deprotonating agents, and simultaneously coordinate with zirconium ions from the other head and act as the nucleation sites for secondary building units (SBUs) production onto the surface of wool [40].

\section{Fourier Transform Infrared Spectroscopy}

Figure 2 presents FTIR spectrum of synthesized Zr-MOF reveals the absorption peaks related to $\mathrm{C}=\mathrm{O}-\mathrm{O}$ symmetric and asymmetric stretching vibrations of carboxylate groups of terephthalic acid at 1400 and $1580 \mathrm{~cm}^{-1}, \mathrm{OH}$ stretching vibrations wide band at $3400 \mathrm{~cm}^{-1}$ corresponded to closely absorbed water molecules and could be originated from zirconium oxychloride octahydrate [41]. Also, O-Zr-O stretching vibrations multiple peaks from 400 to $800 \mathrm{~cm}^{-1}$ indicates formation of octahedral zirconium oxide cluster and $\mathrm{Zr}-\mathrm{O}-\mathrm{C}$ stretching vibrations at $550 \mathrm{~cm}^{-1}$ demonstrates the bridge between the carboxylate groups of terephthalic acid with zirconium oxide cluster [41-43]. These results are in accordance with previous reports also all peaks in the simulated FTIR of Zr-MOF present in the FTIR spectrum of synthesized Zr-MOF confirm the successful synthesis of ZrMOF $[44,45]$. Furthermore, there are no peaks in simulated FTIR as the characteristic peaks of DMF. However, $\mathrm{CH}_{3}$ stretching vibrations at 2990 and $2777 \mathrm{~cm}^{-1}, \mathrm{C}=\mathrm{O}$ stretching

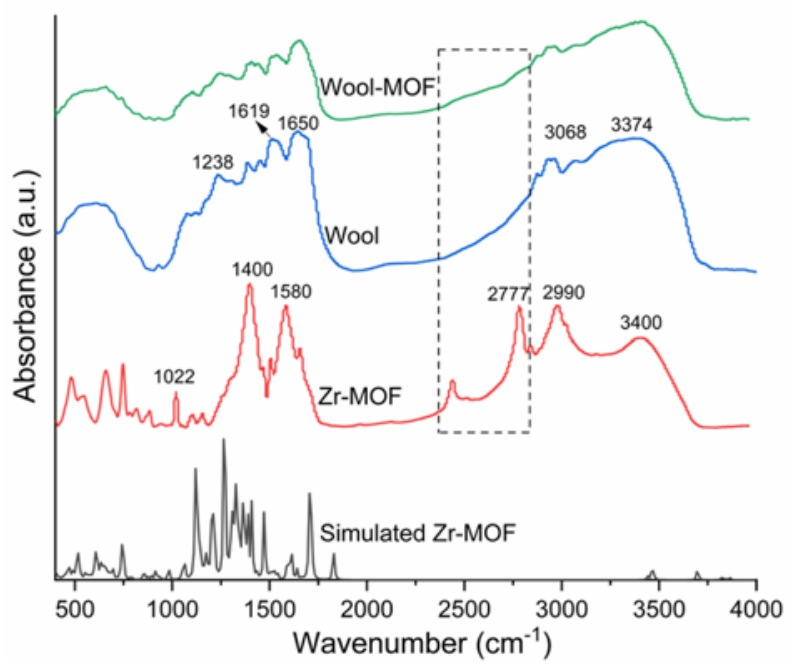

Figure 2. FTIR spectra of simulated Zr-MOF, synthesized ZrMOF, raw wool and wool-MOF samples. 


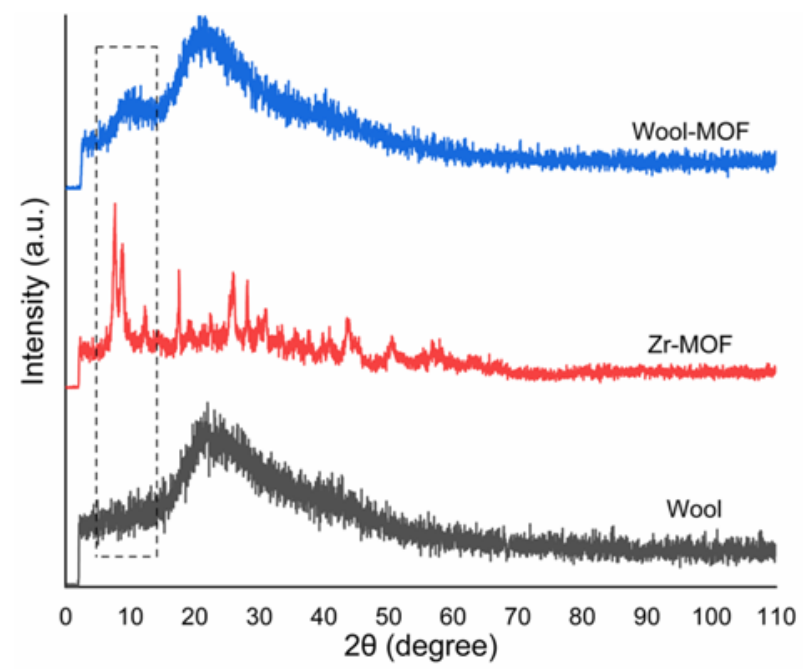

Figure 3. XRD of Zr-MOF powder, raw wool and wool-MOF sample.

vibrations at $1650 \mathrm{~cm}^{-1}$ and $\mathrm{C}-\mathrm{N}$ stretching vibrations at $1022 \mathrm{~cm}^{-1}$ appear in FTIR spectrum of synthesized Zr-MOF suggesting the possible entrapment of DMF inside the MOF structure.

Wool-MOF comprises characteristic peaks of wool related to the peptide bond including amide $\mathrm{A}$ at $3374 \mathrm{~cm}^{-1}$ and amide $\mathrm{B}$ at $3068 \mathrm{~cm}^{-1}$ ascribed to N-H stretching vibrations along with amide I at $1650 \mathrm{~cm}^{-1}$, amide II at $1519 \mathrm{~cm}^{-1}$ and amide III at $1238 \mathrm{~cm}^{-1}[46,47]$. All of these confirm the nucleation of Zr-MOF onto the surface of wool.

\section{X-ray Diffraction Analysis}

Two broad peaks at 21.2 and $23.7^{\circ}$ ascribed to raw wool in Figure 3 [39]. Zr-MOF has several sharp peaks at 7.56, 8.74 and $25.98^{\circ}$ representatively attributed to (111), (002) and (006) planes, indicative of zirconium oxide clusters [4850]. The theoretical crystal size was estimated about $16 \mathrm{~nm}$ by Scherrer equation. Zr-MOF main peaks are obviously emerged in the XRD pattern of wool-MOF evidencing preserved crystalline structure of Zr-MOF onto the surface of wool in agreement with previous research results [39].

\section{Zr-MOF Incorporation Efficiency onto Wool}

The weight of samples increased after synthesis of $\mathrm{Zr}$ MOF due to the weight of incorporated Zr-MOF. The gain in weight of wool-MOF and wool-MOF0.1 was 55 and $40 \%$ indicating that increasing molar ratio of acid decreased the possibility of nucleation in solution due to the more possible coordination with modulator than ligand. Therefore, more $\mathrm{Zr}$-MOF loaded on the surface of wool where can interact with deprotonating groups of wool and nucleate rather than solution. This provides wool-MOF with very low amount of chemicals considerably lower than the typical route used to synthesize Zr-MOF [51].

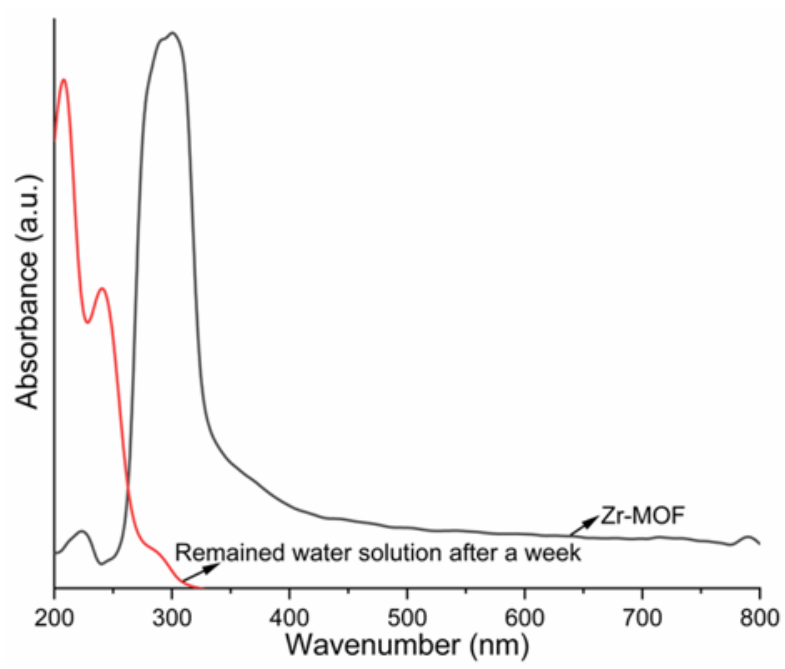

Figure 4. UV-vis spectra of Zr-MOF and wool-MOF waste water.

\section{Washing Durability}

Based on Figure 4, UV-vis spectrum of Zr-MOF shows a band at $300 \mathrm{~nm}$ as typical peak of Zr-MOF [49,50]. The UVvis spectrum of remaining solution of immersed wool-MOF in distilled water after seven days indicates two peaks at 215 and $240 \mathrm{~nm}$ related to DMF and terephthalic acid [52]. Also, the dried wool-MOF sample was weighed and only $3 \%$ weight loss was recorded possibly due to removal of these chemicals. Therefore, Zr-MOF had stronger interactions with functional groups of wool than water molecules, consequently very good washing durability indicated and only the unreacted chemicals removed through washing.

\section{Microscopic Studies}

The Zr-MOF morphology in Figure 5 proves the monodispersed particle size of about $40 \mathrm{~nm}$ which is higher than the theoretically calculated crystal size as a result of inter-growth of crystals that is finely controlled even when they are nucleated onto the fibers [53]. Elemental mapping in Figure 6 shows homogenous distribution of $\mathrm{Zr}-\mathrm{MOF}$ with no growth to build big crystals unevenly. In addition to the $\mathrm{Zr}-\mathrm{MOF}$ main elements, Figure $6 \mathrm{~h}$ confirms the presence of nitrogen and chlorine in $\mathrm{Zr}-\mathrm{MOF}$ powder indicating detention of DMF and zirconium oxychloride inside Zr-MOF cavities. Figure 6i demonstrates $21.78 \%$ sulfur in wool.

\section{Tensile Properties}

Figure 7 demonstrates about $30 \%$ lower tensile strength, $1244 \%$ lower young modulus and $66 \%$ higher strain for the wool-MOF than wool fabric. Tensile strength and elasticity of wool mainly depend on disulfide bonds which partially break during the modification process and cause decrease in young modulus and tensile strength and increase in strain [54]. 

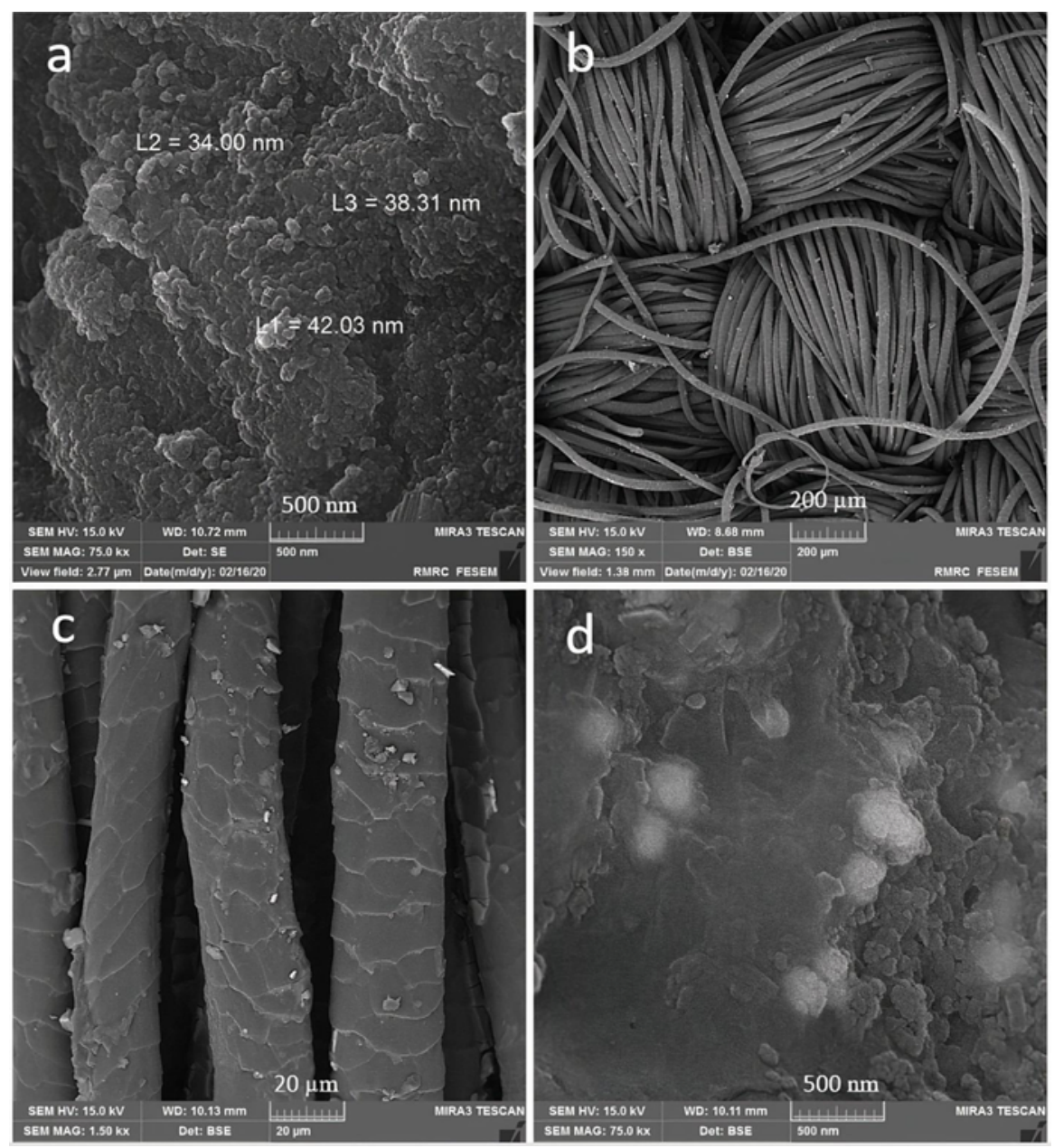

Figure 5. FE-SEM of Zr-MOF powder (a) and FE-SEM of wool-MOF (b-d).

\section{Physical Properties}

Considering that oxygen plays a key role in skin tissue regeneration and prevention of anaerobic bacteria growth, appropriate air-permeation is crucial property for a wound dressing [55]. Air permeability of wool fabric was measured $19 \mathrm{~m} / / \mathrm{s} \cdot \mathrm{cm}^{2}$ while increased up to twice for wool-MOF reached to $40 \mathrm{ml} / \mathrm{s} \cdot \mathrm{cm}^{2}$. According to FE-SEM images (Figure 5), Zr-MOF particles detached wool fibers from each other increased the inter-fiber pores caused the more air to pass through.

While the raw wool fabric absorbs no water drop after $2 \mathrm{~h}$, wool-MOF readily absorb the water drop after $17 \pm 0.86 \mathrm{~s}$. During washing, the wool wax causing hydrophobicity was dissolved triggering fast absorption of water molecules to the fabric. Thus, presence of hydrophilic Zr-MOF and partly eliminating of hydrophobic wool wax led to the more water absorption.

\section{Herbal Extracts Release}

Table 1 shows drastically increase in entrapment efficiency of extracts for samples containing Zr-MOF as a result of high porosity of Zr-MOF making the possibility for extracts to penetrate into $\mathrm{Zr}-\mathrm{MOF}$ cavities. The entrapment efficiency of two samples containing $\mathrm{Zr}-\mathrm{MOF}$ has a linear relation with the amounts of incorporated $\mathrm{Zr}-\mathrm{MOF}$ revealing similar pore size of wool-MOF and wool-MOF0.1 with no missing ligand or node [39].

Figure 8 displays a similar behavior for all the release profiles and samples containing Zr-MOF indicated a controlled burst release for the entrapped extracts. The samples almost released entire loaded extracts after $72 \mathrm{~h}$. All of the drug release models considering swelling or erosion mechanism indicate very poor determined coefficients for various samples substantiating domination of diffusion mechanism for drug release as reported for mesoporous materials [56]. Therefore, for better understanding of release kinetic, Korsmeyer-Peppas model were used as a versatile model for interpreting different drug release mechanisms [57]. Table 2 shows $n$ value of all samples much lower than 0.5 indicating no structural breakdown of $\mathrm{Zr}-\mathrm{MOF}$ in 

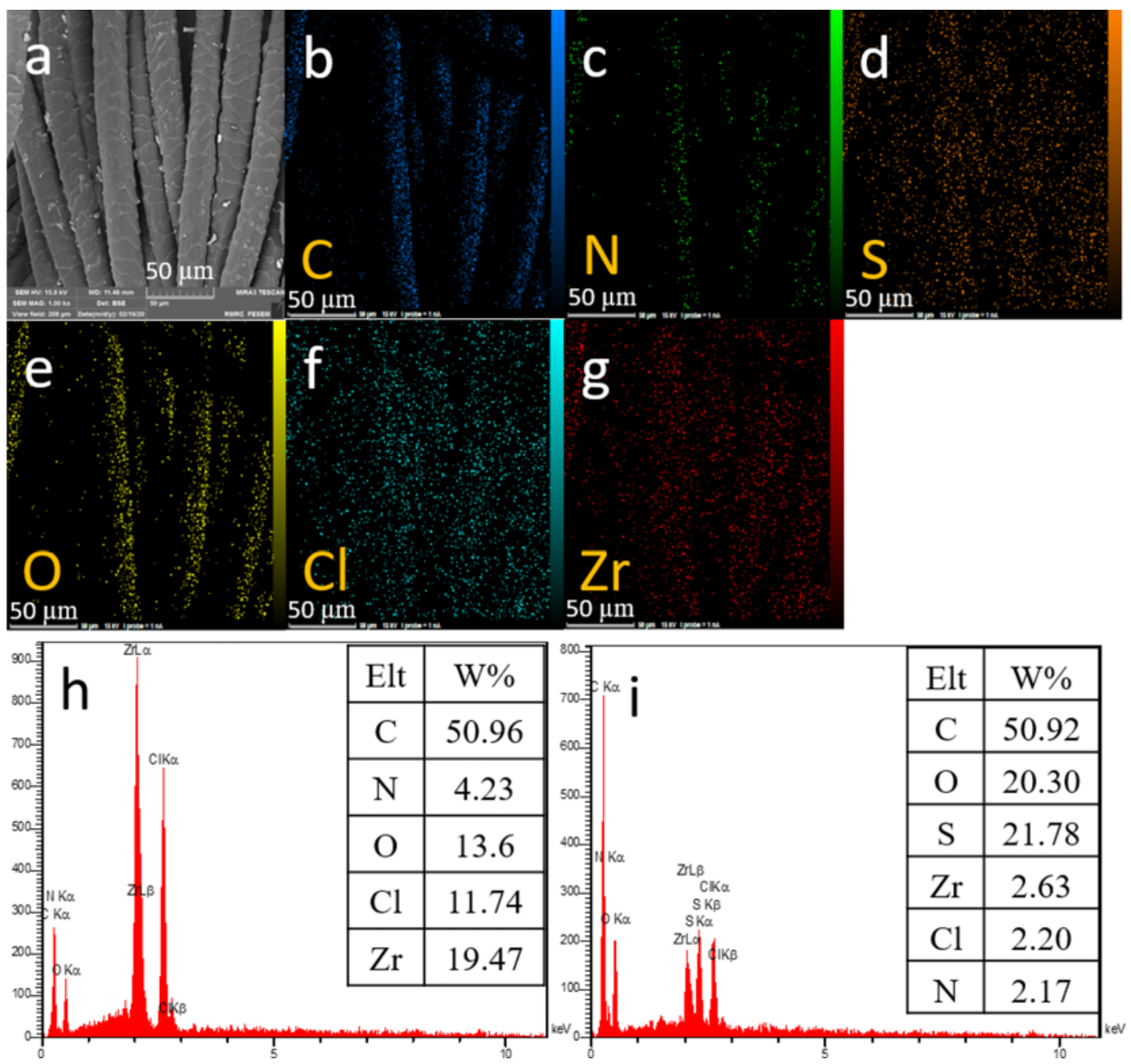

Figure 6. FE-SEM image (a) with 1000x and elemental mapping (b-g), EDX analysis of Zr-MOF powder (h) and wool-MOF (i). (For interpretation of the references to colour in this figure legend, the reader is referred to the web version of this article.)

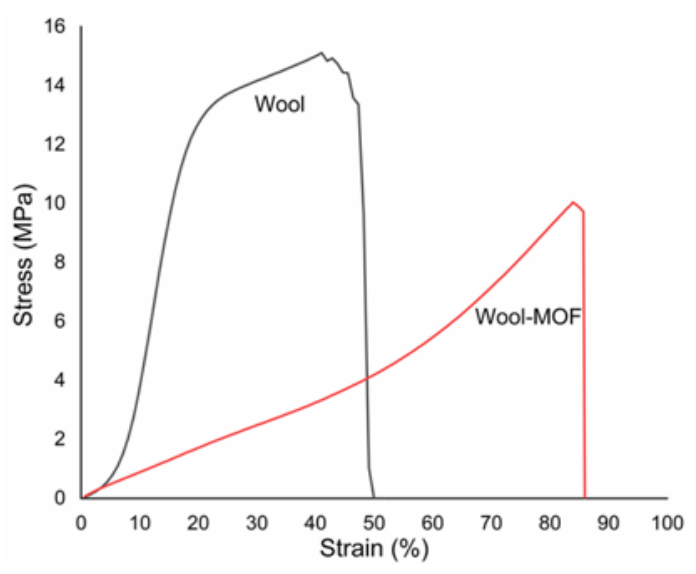

Figure 7. Stress-strain curve of wool fabric and wool-MOF.

presence of herbal extracts and the diffusion governs release mechanism.
Table 1. Entrapment efficiency of Salvia Officinalis and Calendula Officinalis extract in wool fabric, wool-MOF0.1 and wool-MOF

\begin{tabular}{|c|c|c|c|c|}
\hline \multirow[b]{2}{*}{ Sample } & \multicolumn{2}{|c|}{ Salvia Officinalis } & \multicolumn{2}{|c|}{ Calendula Officinalis } \\
\hline & $\begin{array}{c}\text { Loading } \\
(\%)\end{array}$ & $\begin{array}{l}\text { Loaded } \\
\text { sample }\end{array}$ & $\begin{array}{c}\text { Loading } \\
(\%)\end{array}$ & $\begin{array}{l}\text { Loaded } \\
\text { sample }\end{array}$ \\
\hline $\begin{array}{l}\text { Wool } \\
\text { fabric }\end{array}$ & 5.75 & & 3.09 & \\
\hline $\begin{array}{l}\text { Wool- } \\
\text { MOF0.1 }\end{array}$ & 51.02 & & 41.66 & \\
\hline Wool-MOF & 66.40 & & 56.92 & \\
\hline
\end{tabular}



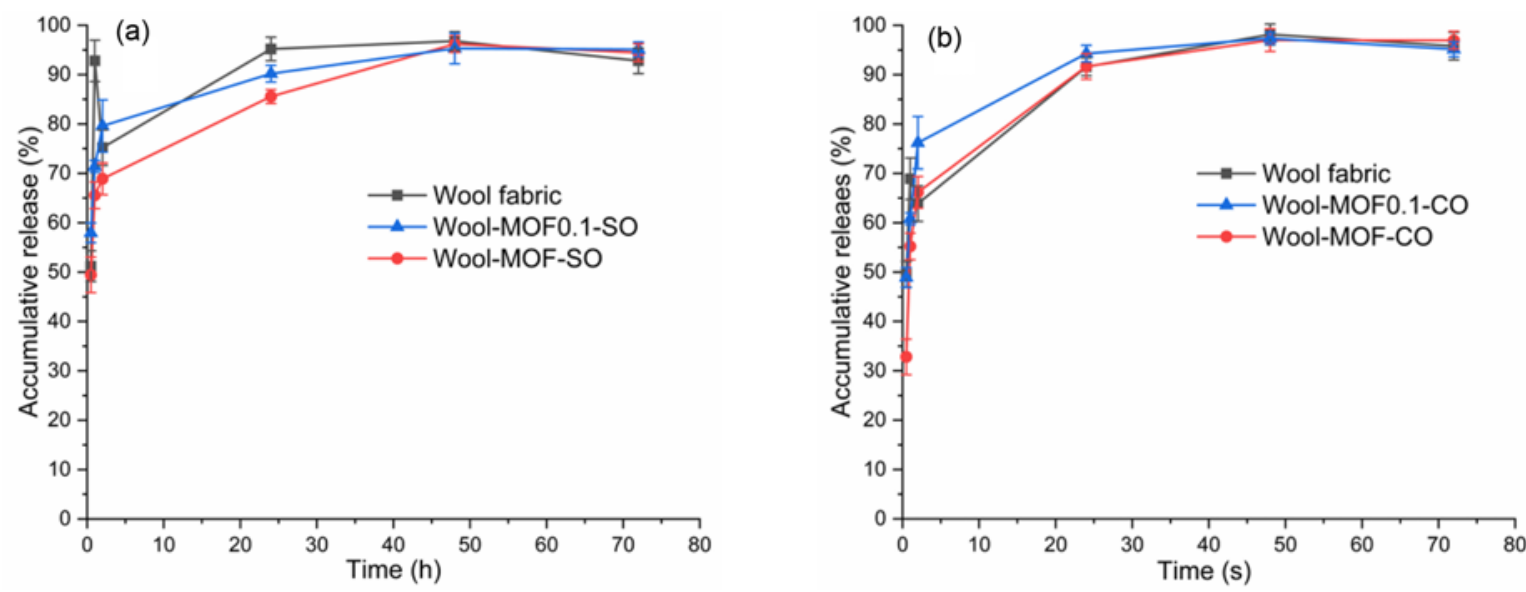

Figure 8. Release profile from wool-SO, wool-MOF0.1-SO and wool-MOF1-SO (a) and wool-CO, wool-MOF0.1-CO and WoolMOF1-Co (b).

Table 2. Korsmeyer-Peppas model parameters for extract release from samples

\begin{tabular}{lcc}
\hline \multicolumn{1}{c}{ Sample } & $\mathrm{n}$ & $\mathrm{R}^{2}$ \\
\hline Wool-SO & 0.07 & 51.17 \\
Wool-MOF0.1-SO & 0.08 & 88.33 \\
Wool-MOF-SO & 0.11 & 94.17 \\
Wool-CO & 0.11 & 92.50 \\
Wool-MOF0.1-CO & 0.14 & 78.98 \\
Wool-MOF1-CO & 0.16 & 90.57
\end{tabular}

\section{Antibacterial Activity and Cytotoxicity}

Salvia Officinalis extract is mainly constituted of 1,8 cineole, $\alpha$-Thujone, $\beta$-Thujone, camphor, viridiflorol also some flavonoids, $\beta$-caryophyllene and $\alpha$-humulene [58]. Calendula Officinalis extract largely comprises cadinene, $\alpha-$ cadinol and some $\alpha$-humulene and flavonoids [59]. 1,8 cineole and viridiflorol have antibacterial activity also $\beta$ caryophyllene, $\alpha$-humulene and all flavonoids specially flavonols are toxic inducing cell death [60-63]. Zr-MOFs indicate no antibacterial activity [64].

Figure 9 demonstrates antibacterial activity and cytotoxicity

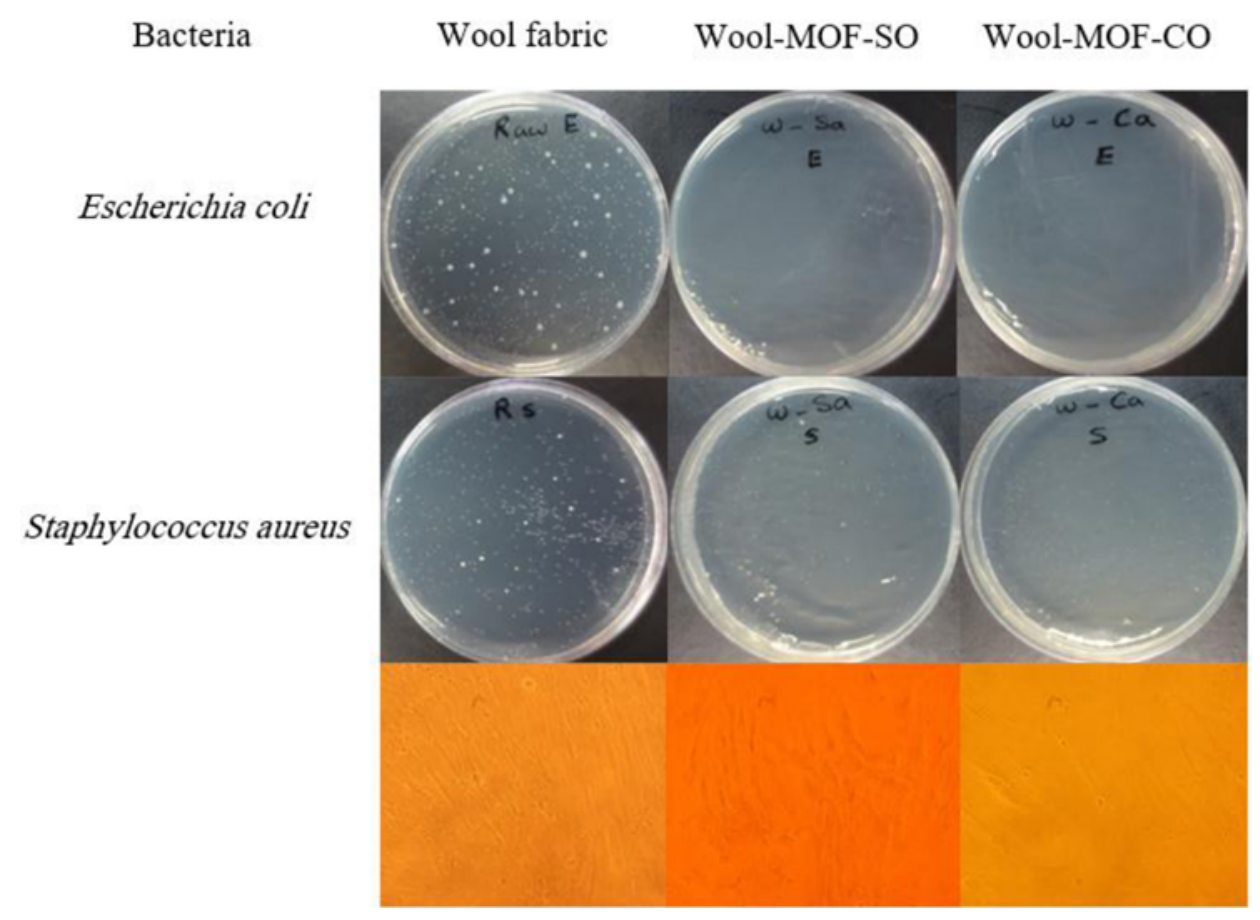

Figure 9. Antibacterial activity and cytotoxicity of wool fabric, wool-MOF-SO and wool-MOF-CO. 
of wool-MOF samples containing Salvia Officinalis (woolMOF-SO) and Calendula Officinalis (wool-MOF-CO). Both wool-MOF-SO and CO indicated $100 \%$ antibacterial activity against Gram negative and Gram positive model bacteria 60.95 and $64.64 \%$, respectively due to the high amounts of antibacterial components.

Effect of biomaterials on cell viability is an important parameter for biomedical applications. According to ISO 10993-5 standard more than $70 \%$ cell viability indicates biocompatibility. Therefore, results prove that wool-MOF$\mathrm{CO}$ is not toxic showing $82.01 \%$ cell viability as a confidently biocompatible material. However, wool-MOFSO indicates $33.61 \%$ cell viability with high potency for inducing death to cancer cells [65]. The toxic components of Salvia Officinalis extract are twice as Calendula Officinalis extract which can justify the obtained results [30].

\section{Conclusion}

In this work, Zr-MOF was synthesized onto the wool fabric through in-situ one-pot method. Through diverse methods the successful monodisperse nucleation of $\mathrm{Zr}-\mathrm{MOF}$ onto the wool fabric was proved. It was demonstrated that while concentration of acid remains unchanged with increasing acid molar ratio, the tendency of nucleation onto surface of wool increases. The wool-MOF air-permeability increased up to twice and the hydrophobic surface of wool fabric changed to hydrophilic because of presence of hydrophilic Zr-MOF and removal of hydrophobic wool wax. The fabric tensile strength and young modulus decreased and strain increased due to partial breakage of disulfide bonds. The release profile of Salvia Officinalis and Calendula Officinalis extracts was similar and the release mechanism was governed by diffusion. Both wool-MOF-SO and or absolute antibacterial activity $100 \%$ showed antibacterial activity against Escherichia coli, Gram negative model bacterium, and 60.95 and $64.64 \%$ against Staphylococcus aureus, Gram positive model bacterium. Wool-MOF-CO was a biocompatible material however wool-MOF-SO exhibited high toxicity due to high toxic components. The results of this research, pave the way for further researches on improvement of wound healing and anticancer properties of the herbal extracts using $\mathrm{Zr}-\mathrm{MOF}$ onto the textile surface.

\section{Acknowledgements}

This research did not receive any specific grant from funding agencies in the public, commercial, or not-for-profit sectors.

\section{References}

1. F. Moradi Kashkooli, M. Soltani, and M. Souri, J. Control.
Release, 327, 316 (2020).

2. M. E. Fortes Brollo, A. Domínguez-Bajo, A. Tabero, V. Domínguez-Arca, V. Gisbert, G. Prieto, C. Johansson, R. Garcia, A. Villanueva, M. C. Serrano, and M. del P. Morales, ACS Appl. Mater. Interfaces, 12, 4295 (2020).

3. M. K. Haidar, S. S. Timur, G. M. Demirbolat, E. Nemutlu, R. N. Gürsoy, K. Ulubayram, L. Öner, and H. Eroğlu, Fiber. Polym., 22, 334 (2021).

4. B. Wang, J. Wang, J. Shao, P. H. J. Kouwer, E. M. Bronkhorst, J. A. Jansen, X. F. Walboomers, and F. Yang, J. Control. Release, 324, 134 (2020).

5. F. Zhou, S. Wu, C. Rader, J. Ma, S. Chen, X. Yuan, and E. J. Foster, Fiber. Polym., 21, 45 (2020).

6. C. A. R. Chapman, E. A. Cuttaz, J. A. Goding, and R. A. Green, Appl. Phys. Lett., 116, 10501 (2020).

7. W. Yu, R. Liu, Y. Zhou, and H. Gao, ACS Cent. Sci., 6, 100 (2020).

8. Y. Tang, L. Liu, J. Han, Z. Zhang, S. Yang, S. Li, Z. Fan, and H. Zhao, Fiber. Polym., 22, 323 (2021).

9. M. Kumar, S. Pandey, A. Swami, N. Wangoo, Saima, R. Jain, and R. K. Sharma, ACS Appl. Bio Mater, 3, 1913 (2020).

10. J. Nourmohammadi, M. Hadidi, M. H. Nazarpak, M. Mansouri, and M. Hasannasab, Fiber. Polym., 21, 456 (2020).

11. J. Jenkins, J. Mantell, C. Neal, A. Gholinia, P. Verkade, A. H. Nobbs, and B. Su, Nat. Commun., 11, 1626 (2020).

12. C. E. Wilmer, M. Leaf, C. Y. Lee, O. K. Farha, B. G. Hauser, J. T. Hupp, and R. Q. Snurr, Nat. Chem., 4, 83 (2012).

13. X. Xiao, L. Ren, S. Wang, Q. Zhang, Y. Zhang, R. Liu, and W. Xu, Fiber. Polym., 21, 2003 (2020).

14. J. H. Cavka, S. Jakobsen, U. Olsbye, N. Guillou, C. Lamberti, S. Bordiga, and K. P. Lillerud, J. Am. Chem. Soc., 130, 13850 (2008).

15. V. V. Butova, M. A. Soldatov, A. A. Guda, K. A. Lomachenko, and C. Lamberti, Russ. Chem. Rev., 85, 280 (2016).

16. M. R. Ramezani, Z. Ansari-Asl, E. Hoveizi, and A. R. Kiasat, Fiber. Polym., 21, 1013 (2020).

17. A. Schoedel and O. M. Yaghi, "Macrocyclic and Supramolecular Chemistry: How Izatt-Christensen Award Winners Shaped the Field", 1st ed., Wiley, New York, 2016.

18. P. Falcaro, R. Ricco, C. M. Doherty, K. Liang, A. J. Hill, and M. J. Styles, Chem. Soc. Rev., 43, 5513 (2014).

19. M. Kandiah, M. H. Nilsen, S. Usseglio, S. Jakobsen, U. Olsbye, M. Tilset, C. Larabi, E. A. Quadrelli, F. Bonino, and K. P. Lillerud, Chem. Mater., 22, 6632 (2010).

20. R. M. Abdelhameed, E. Alzahrani, A. A. Shaltout, and H. E. Emam, J. Ind. Eng. Chem., 94, 134 (2021).

21. H. E. Emam, H. B. Ahmed, E. Gomaa, M. H. Helal, and R. M. Abdelhameed, Cellulose, 27, 7139 (2020).

22. H. E. Emam, F. H. H. Abdellatif, and R. M. Abdelhameed, J. Clean. Prod., 178, 457 (2018). 
23. H. E. Emam, O. M. Darwesh, and R. M. Abdelhameed, Ind. Eng. Chem. Res., 59, 10931 (2020).

24. R. M. Abdelhameed, M. El-Shahat, and H. E. Emam, Carbohydr. Polym., 247, 116695 (2020).

25. M. A. Bunge, A. B. Davis, K. N. West, C. W. West, and T. G. Glover, Ind. Eng. Chem. Res., 57, 9151 (2018).

26. W.-Y. Qian, D.-M. Sun, R.-R. Zhu, X.-L. Du, H. Liu, and S.-L. Wang, Int. J. Nanomedicine, 7, 5781 (2012).

27. A. Shirwaikar, A. Shirwaikar, S. L. Prabu, and G. A. Kumar, Indian J. Pharm. Sci., 70, 415 (2008).

28. K. J. Srivastava, E. Shankar, and S. Gupta, Mol. Med. Rep., 3, 895 (2010).

29. M. Hamidpour, R. Hamidpour, S. Hamidpour, and M. Shahlari, J. Tradit. Complement. Med., 4, 82 (2014).

30. G. Miliauskas, P. R. Venskutonis, and T. A. van Beek, Food Chem., 85, 231 (2004).

31. M. Fronza, B. Heinzmann, M. Hamburger, S. Laufer, and I. Merfort, J. Ethnopharmacol., 126, 463 (2009).

32. S. Moradkhani, I. Salehi, S. Abdolmaleki, and A. Komaki, Anc. Sci. Life, 34, 156 (2015).

33. D. Arora, A. Rani, and A. Sharma, Pharmacogn. Rev., 7, 179 (2013).

34. M. J. Leach, Wounds a Compend. Clin. Res. Pract., 20, 236 (2008).

35. N. Tanideh, V. Ghafari, R. Ebrahimi, R. Habibagahi, O. Koohi-Hosseinabadi, and A. Iraji, J. Dent., 21, 314 (2020).

36. B. Bozin, N. Mimica-Dukic, I. Samojlik, and E. Jovin, J. Agric. Food Chem., 55, 7879 (2007).

37. P. Das, R. Majumder, M. Mandal, and P. Basak, J. Biomol. Struct. Dyn., doi.org/10.1080/07391102.2020.1796799 (2020).

38. A. Balkrishna, R. Mittal, and V. Arya, Curr. Pharm. Biotechnol., doi.org/10.2174/1389201021999201110204116 (2020).

39. R. M. Abdelhameed, H. R. el-deib, F. M. S. E. El-Dars, H. B. Ahmed, and H. E. Emam, Ind. Eng. Chem. Res., 57, 15054 (2018).

40. H. E. Emam, H. B. Ahmed, H. R. El-Deib, F. M. S. E. ElDars, and R. M. Abdelhameed, J. Colloid Interface Sci., 556, 193 (2019).

41. J. Ding, Z. Yang, C. He, X. Tong, Y. Li, X. Niu, and H. Zhang, J. Colloid Interface Sci., 497, 126 (2017).

42. K. Vellingiri, A. Deep, K.-H. Kim, D. W. Boukhvalov, P. Kumar, and Q. Yao, Sensors Actuators B Chem., 241, 938 (2017).

43. J. Yang, Y. Dai, X. Zhu, Z. Wang, Y. Li, Q. Zhuang, J. Shi, and J. Gu, J. Mater. Chem. A, 3, 7445 (2015).

44. J. Yang, X. Chen, Y. Li, Q. Zhuang, P. Liu, and J. Gu, Chem. Mater, 29, 4580 (2017).

45. R. M. Abdelhameed, M. Rehan, and H. E. Emam,
Carbohydr. Polym., 195, 460 (2018).

46. K. Wang, R. Li, J. H. Ma, Y. K. Jian, and J. N. Che, Green Chem., 18, 476 (2016).

47. H. Barani, A. Haji, and H. Maleki, Int. J. Biol. Macromol., 108, 585 (2018).

48. A. Farboudi, K. Mahboobnia, F. Chogan, M. Karimi, A. Askari, S. Banihashem, S. Davaran, and M. Irani, Int. J. Biol. Macromol., 150, 178 (2020).

49. M. J. Katz, Z. J. Brown, Y. J. Colón, P. W. Siu, K. A. Scheidt, R. Q. Snurr, J. T. Hupp, and O. K. Farha, Chem. Commun., 49, 9449 (2013).

50. M. Massoudinejad, M. Ghaderpoori, A. Shahsavani, and M. M. Amini, J. Mol. Liq., 221, 279 (2016).

51. M. A. Bunge, A. B. Davis, K. N. West, C. W. West, and T. G. Glover, Ind. Eng. Chem. Res., 57, 9151 (2018).

52. V. Vaiano, G. Sarno, O. Sacco, and D. Sannino, Chem. Eng. J., 312, 10 (2017).

53. J. Ren, H. W. Langmi, B. C. North, M. Mathe, and D. Bessarabov, Int. J. Hydrogen Energy, 39, 890 (2014).

54. B. Aksakal, V. Alekberov, Fiber. Polym., 10, 673 (2009).

55. Y. Yang and H. Hu, Text. Res. J., 87, 1481 (2016).

56. A. Zhokh and P. Strizhak, Microporous Mesoporous Mater, 282, 22 (2019).

57. M. Bruschi, "Strategies to Modify the Drug Release from Pharmaceutical Systems", 1st ed. Woodhead Publishing, Netherland, 2015.

58. S. K. El Euch, D. B. Hassine, S. Cazaux, N. Bouzouita, and J. Bouajila, South African J. Bot., 120, 253 (2019).

59. Z. C. Gazim, C. M. Rezende, S. R. Fraga, B. P. Dias Filho, C. V. Nakamura, and D. A. G. Cortez, Rev. Bras. Ciências Farm., 44, 391 (2008).

60. S. Murata, R. Shiragami, C. Kosugi, T. Tezuka, M. Yamazaki, A. Hirano, Y. Yoshimura, M. Suzuki, K. Shuto, N. Ohkohchi, and K. Koda, Oncol. Rep., 30, 2647 (2013).

61. L. N. F. Trevizan, K. F. Nascimento, J. A. Santos, C. A. L. Kassuya, C. A. L. Cardoso, M. do C. Vieira, F. M. F. Moreira, J. Croda, and A. S. N. Formagio, J. Ethnopharmacol., 192, 510 (2016).

62. A. P. Longaray Delamare, I. T. Moschen-Pistorello, L. Artico, L. Atti-Serafini, and S. Echeverrigaray, Food Chem., 100, 603 (2007).

63. S. F. van. Vuuren and A. M. Viljoen, Flavour Fragr. J., 22, 540 (2007).

64. M. Nasrabadi, M. A. Ghasemzadeh, and M. R. Zand Monfared, New J. Chem., 43, 16033 (2019).

65. A. El Hadri, M. A. G. del Rio, J. Sanz, A. G. Coloma, M. Idaomar, B. R. Ozonas, J. B. González, and M. I. S. Reus, An. R Acad Nac. Farm., 76, 343 (2010). 